\title{
A Study of Typhoon Rainbands with Quantitized Radar Data
}

\author{
By Takehiko Furukawa \\ Meteorological Research Institute, Tsukuba \\ (Manuscript received 10 February 1979, in revised form 26 June 1980)
}

\begin{abstract}
Conventional PPI radar echoes which were associated with Typhoon 7617 in September 1976 are quantitized in the form of an echo coverage within a $10 \mathrm{~km}$ square grid over the area of $400 \times 400 \mathrm{~km}$. A mean state of radar rainbands (MRB) which lies from sea to land and variability in the time series of echo coverage are discussed in connection with the rainfall amounts obtained by raingauges. The area of significant rainfall is in average concentrated into a few narrow bands which run almost parallel to the prevailing wind of the typhoon circulation. A main rainband runs perpendicularly to land, Shikoku with increasing its intensity and west-east width.

A uniform magnitude of the variance with time and a predominant period with the order of one hour are obtained for the rain activity in the MRB. The two-dimensional (timespace) spectral analysis shows that the MRB consists of organized convective rain complexes with the predominant period of one hour. The complexes travel with the speed of about $20 \mathrm{~m} / \mathrm{sec}$ and are separated longitudinally by about $50-100 \mathrm{~km}$ in the MRB.
\end{abstract}

\section{Introduction}

It has been well experienced that rainfalls over land accompanied by a typhoon are crutially affected by the intensity and the movement of precipitation bands. There are many documents which concern such rainfalls. For example, analyses of rainfalls by staff members of Tokyo University $(1969,1970)$ showed the existence of precipitation bands over land which corresponds to a group of radar rainbands. It was also shown that when radar rainbands are over a mountain range, the precipitation amount and its variability with time is very much enhanced. Sakakibara and Takeda (1973) studied orographic effects upon rainbands. They showed the existence of several rainbands travelling over a mountain range and that the rainfalls are enhanced by an amplification factor due to the orography against the rainfalls if there is no orographic effect. Suzuki (1961) proposed a climatological rainfall distribution over Shikoku associated with typhoons by taking account of orographic effect. Ninomiya (1977) showed that a heavy rainfall area accompanied by a typhoon moves over the main mountain range in south Shikoku depending or: the change of the surface winds due to the move- ment of typhoon. He suggested that a forced uplift due to the orography has an important effect upon heavy rainfalls. On the other hand, the kinematics of echo cells and rainbands have been discussed by many authors. Senn and Hiser (1959) studied in detail the kinematics of echo cells embedded in harricane circulation and showed that several characteristic features of spiral rainbands. Tatehira $(1961,1962)$ also studied the formation and the movement of individual echo cells constituting spiral rainbands of typhoons and related pressure, horizontal convergence and precipitation fields.

For the understanding of orographic effects upon rainfalls accompanied by typhoons, it is desirable to study how rainbands are influenced by orography over a broad area including land and sea. The conventional raingauge data are not sufficient for these purposes. So far it seems that most studies have been intended to analyze raingauge data over land by various kinds of techniques and to distinguish the orographic rain and the convective rain. Ninomiya and Akiyama (1974) and Akiyama (1974) tried to quantitize radar data to facilitate the study of mesoscale features in rainbands, especially in Baiu front. In the quantitative analysis of rainfalls, however, 
radar data have usually been utilized as a subsidiary tool. We feel this comes from the difficulty that it needs laborious process to quantitize radar data into fruitful information. It is needless to mention that a meteorological radar has advantages to ascertain rain activity over a broad range and to produce continuous data for both space and time. In this paper we have performed a quantitization of radar pictures. The purpose of this paper is to describe the horizontal and the time scales of rainfalls associated with typhoons by quantitizing PPI radar data.

Typhoon 7617 brought remarkably heavy rainfalls over western Japan in September 1976. The truck of the typhoon is shown in Fig. 1. The typhoon moved very slowly over the sea near southern Kyushu and almost stayed during the period 0300 to 1500 JST on 11 September. The total amount of rainfall during the passage of the typhoon reached more than $1,800 \mathrm{~mm}$ at many raingauge stations in southern Shikoku. The lives of more than 130 people were lost by the floods and landslides caused by the torrential

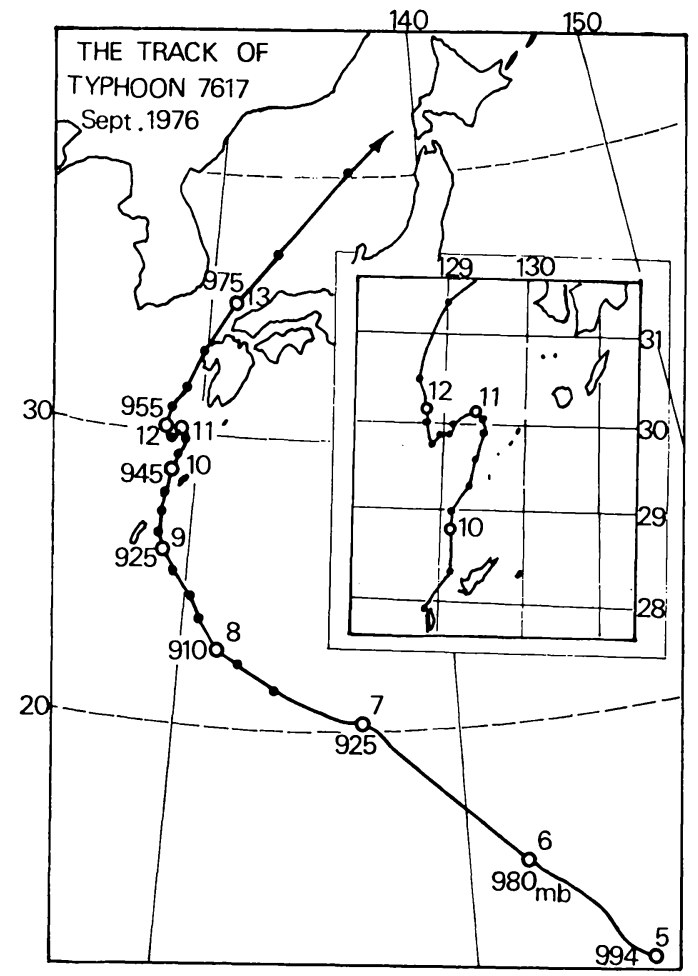

Fig. 1 The track of Typhoon 7617 from 5 to 13 September 1976. The central pressure at 0900 JST on each day is presented. The small figure denotes track for a three hour interval. rain. We have collected meteorological data for the typhoon including radar cinefilms, in cooperation with the Ocean Research Institute, University of Tokyo. We selected the rainfalls over Shikoku accompanied by this typhoon as a typical example of our concern. We treated the radar data taken at Murotomisaki Weather Station (M-station) for the surveillance of Typhoon 7617. Main concerns were directed to understanding the rain activity during the six hours from 0900 to 1500 JST 11 September 1976. In Fig. 2 we show the flow chart of the studies in this paper.

\section{Preliminary analysis of rainfalls}

Before quantitizing the data of the PPI radar echo into the form of an echo coverage and analyzing them, we shall first look at the characteristics of rainfalls revealed by conventional raingauge over Shikoku. The total rainfall amount for the six hours from 0900 to 1500 JST 11 September 1976 is shown in Fig. 3. It is interesting to note that there are some isolated banded structures in the rainfall amounts in Fig. 3. We indicate three horizontal scales in the six hour rainfall-distribution. First, we see a macroscopic rain belt with the width of about $200 \mathrm{~km}$ in the west-east direction. The belt, which is characterized by the contours of weak rainfall amounts of $10 \mathrm{~mm} / 6$ hours or more, has clear edges at the western and eastern sides. This is justified by the analysis of the rainfall distribution over western Japan. Second, we see that there exist three longitudinal zones (stippled and defined by contours of $50 \mathrm{~mm} / 6$ hours or more) in the belt. It is noted that the central and the eastern zones extend across the Shikoku mountain chains toward Seto Inland Sea from Tosa Bay in the Pacific. Third, we recognize remarkably heavy rainbands which are concentrated into a few narrow longitudinal bands with the width of several tens of kilometers. This is well seen for the central rainband by the contours $100 \mathrm{~mm} /$ 6 hours in the central zone. In the central rainband the maximum rainfall amount reaches about $200 \mathrm{~mm} / 6$ hours in a mountain range. We see a similar rainband in the east rainfall zone with the maximum of $300 \mathrm{~mm} / 6$ hours over a mountain range. The three characteristics above are for the 6 hour-rainfall amounts. The terms, belt, zone and band were referred to describe the rainfall distribution characteristically. Later a physical interpretation will be made for this classification.

Next we shall describe an hourly rainfall 


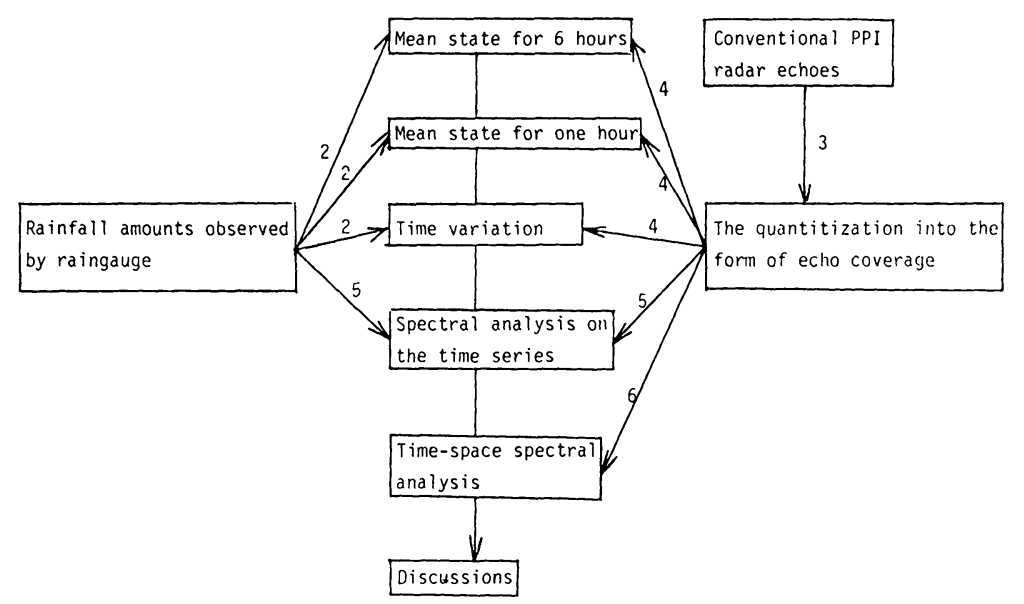

Fig. 2 The flow chart of the present analysis. The numerals show the section number discussed.

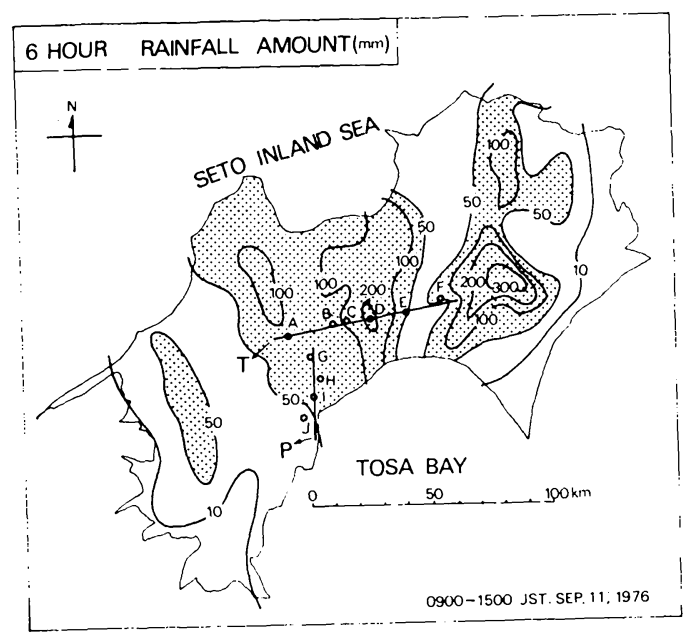

Fig. 3 The total rainfall amounts for the six hours from 0900 to 1500 JST on 11 September 1976.

distribution. The hourly rainfall amount from 1100 to 1200 JST 11 September is shown as an example in Fig. 4. It is important to note that we can recognize three similar scales in the hourly rainfall distribution to those revealed in the 6 hour rainfall distribution in Fig. 3. The magnitudes of the contours which define the three scales in the hourly rainfall decrease to almost one-fifth of the magnitudes of the 6 hour rainfall amounts. That is, the macroscopic rain belt is defined by the contours $2 \mathrm{~mm} /$ hour, the threc longitudinal zones (stippled) are recognized by the contours $10 \mathrm{~mm} /$ hour and several rainbands which are more localized than those in the 6 hour rainfall distribution are analyzed. These three

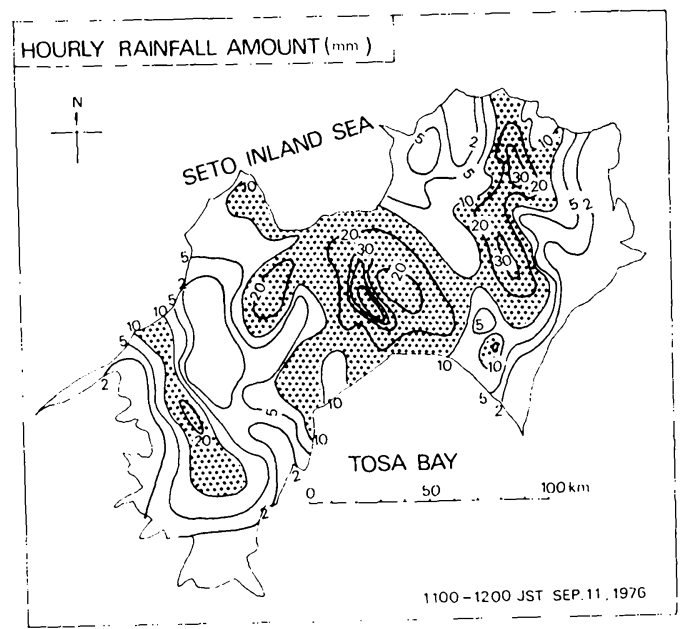

Fig. 4 Hourly rainfalls from 1100 to 1200 JST on 11 September 1976.

features lead to the following. Major rainfall activity is confined to a few rainbands which orient longitudinally over Shikoku in the zones. Such a stationary band and zone structure suggests an existence of an orographic effect upon an organization of rainfall. At the same time we feel that it is necessary to see how such a structure is formed over Tosa Bay in the Pacific.

We show time variations of 10 -minute rainfall amounts at the stations along the two lines denoted by $T$ and $P$ in Fig. 3. The line $T$ crosses the central rainfall zone transversally and the line $P$ lies longitudinally in a peripheral area of the central zone. At a glance in Fig. 5 we notice that the rainfall activity is highly pulsative for all the stations. That is, the rainfall is greatly 

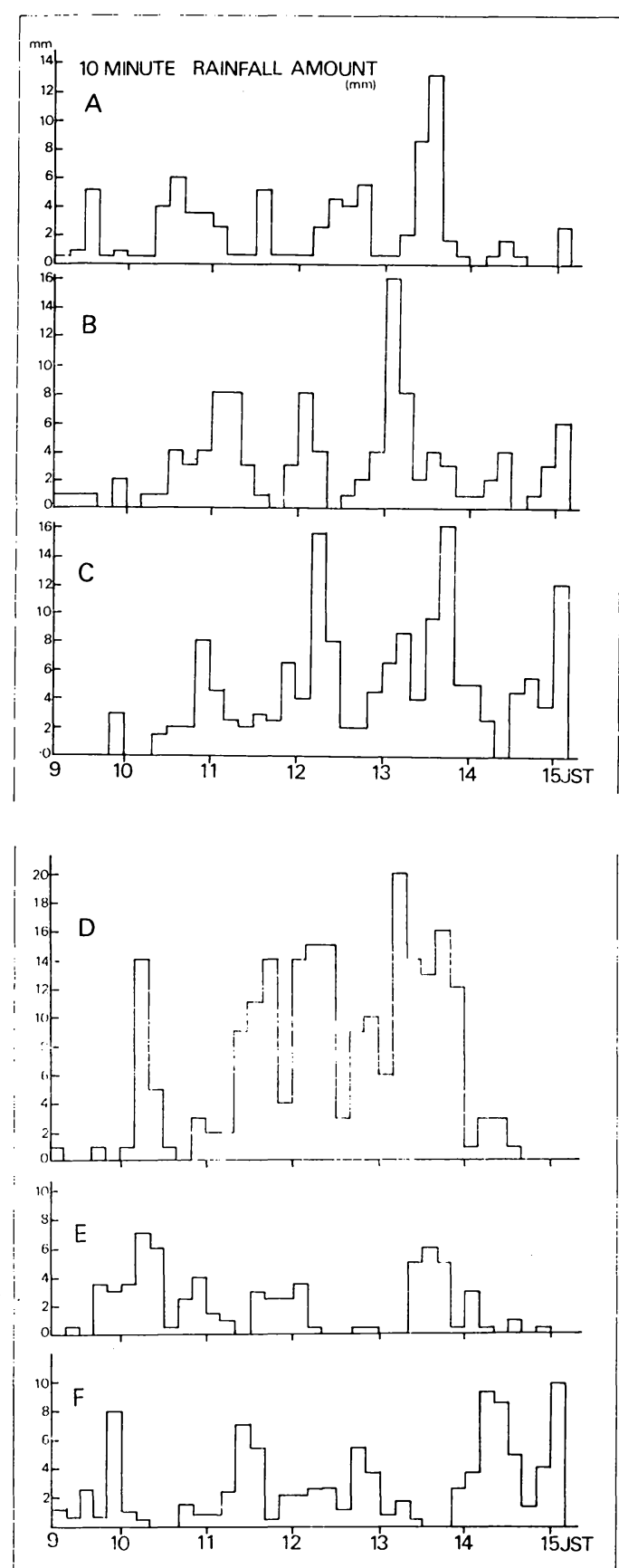

Fig. 5 Time variations of 10-minute rainfalls. The capital letters A-F present the stations which are located along the line $T$ shown in Fig. 3.

characterized by cumulus convections. Torrential rainfalls with the rainfall intensity $50 \mathrm{~mm} /$ hour are seen at Station D which is located in the midst of the central rainband. The records at

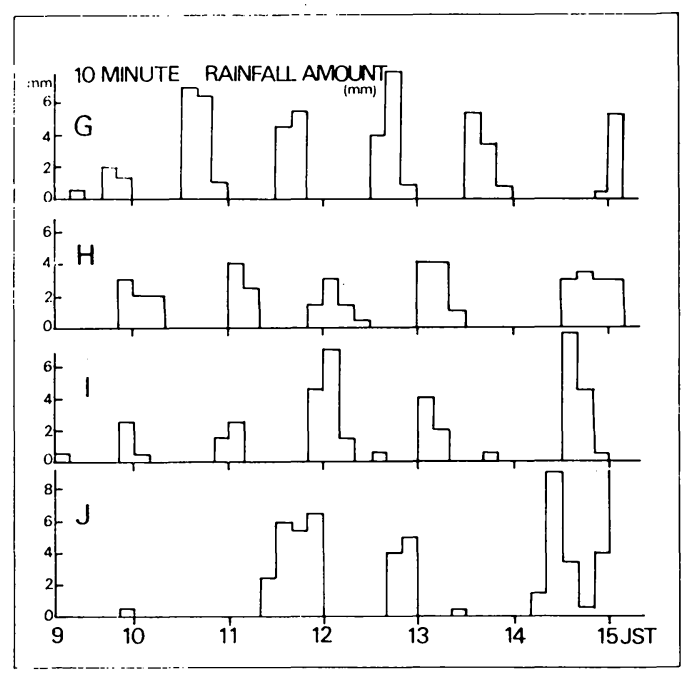

Fig. 6 Similar to Fig. 5 but for the stations G-J along the line $P$.

Station B and C show similar time variations at D. It suggests that a characteristic west-east extent of cumulus convection is on the order of a few tens of kilometers. It is noted that there exist continuous rainfalls between pulsative rainfalls at Stations C and D in the core area of the rainband. In the peripheral area, however, the continuous rainfall decreases remarkably at Stations A, B, E and F. This is well seen at the stations along the line $P$. In Fig. 6 we see a series of amazingly regular convective rainfalls with the intensity of about $20-30 \mathrm{~mm} /$ hour. The rainfall seems to be intermittent with the period of one hour and the convective rainfall areas move northward with a speed of about $50 \mathrm{~km} /$ hour. Such a movement is not clear in the core area in the central rain zone.

Next let us examine a satellite picture. Fig. 7 shows the IR-imaged picture taken from NOAA 4 at 2056 JST 11 September. We see a large scale cloud belt lying over Tosa Bay in the Pacific. The width of the belt increases toward north and the belt covers Shikoku (Note that the observational time of the satellite picture is 9 hours later than the midtime of our analysis period). It is interesting to note that the macroscopic rain belts which were revealed by the two time scales, 1 and 6 hours in Figs. 3 and 4, have the same width as that of the cloud belt recognized over Shikoku by the satellite. The cloud belt is considered as a part of the outer spiral bands associated with Typhoon 7617 .

Now we have several questions to be answered 


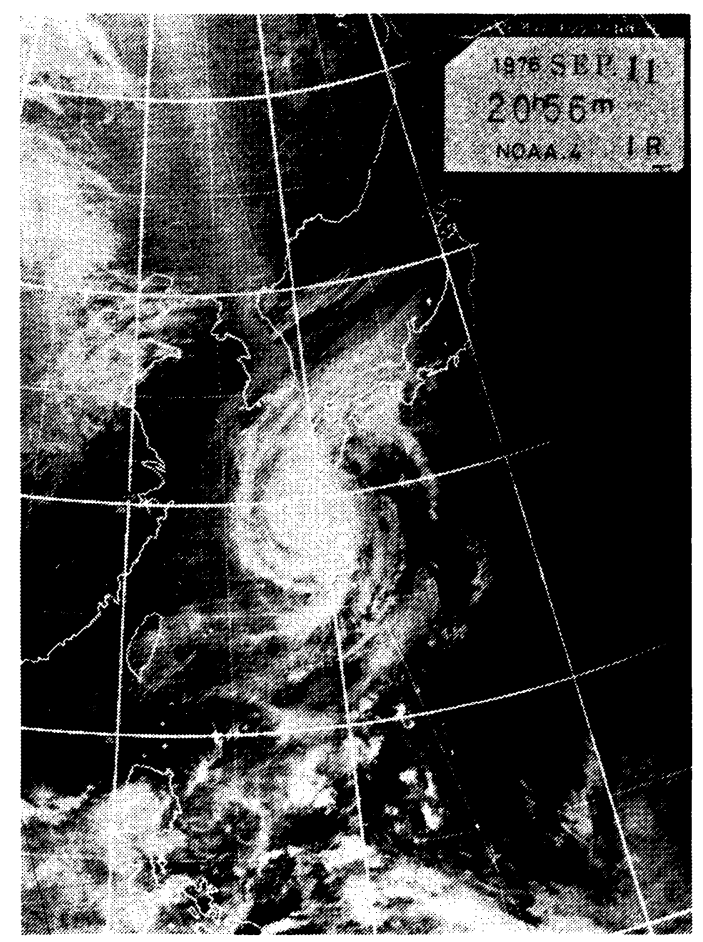

Fig. 7 NOAA 4 IR photo at 2056 JST on 11 September 1976.

as follows. How does exist the concentration of the rainfall into a narrow band over Shikoku and how does the concentration initiate over Tosa Bay in the Pacific? Is there any predominant period in rainfall activity over the Bay? Is the period different over an ocean to over a land or a mountain range? Can we recognize the existence of a convective rain complex in a rainband? The quantitative description of rainfall activity in the whole region above is needed to understand the effect of topography upon rainfalls.

\section{The method of quantitization of a radar echo}

Principal specifications of Murotomisaki radar are as follows: the wavelength $5.66 \mathrm{~cm}$, the horizontal and vertical beam-width $1.3^{\circ}$ and $1.5^{\circ}$, the maximum PPI detecting range $400 \mathrm{~km}$ and the height of antenna $199 \mathrm{~m}$ above m.s.l. The elevation angle and detecting range (PPI) are set at $1.5^{\circ}$ and $300 \mathrm{~km}$ during the observation of Typhoon 7617. PPI observation is made at gainlevels $0,2,4$ and 6 . The levels 2,4 and 6 correspond to rainfall intensity 1,4 and $16 \mathrm{~mm} /$ hour, respectively. The level 0 denotes full gain. The minimum detective height depends on the elevation angle and the radius from the radar station. This height is about $3 \mathrm{~km}$ at the radius of $100 \mathrm{~km}$, and $7.5 \mathrm{~km}$ at that of $200 \mathrm{~km}$ due to the set of the elevation angle $\left(1.5^{\circ}\right)$. Therefore the ground echoes were almost eliminated. It should be noted that echoes tends to be underestimated in a distant region since low clouds can not be detected. This leads to an underestimation of the horizontal extent of rain activity. The time intervals of the observations were not regular but were approximately 6 minutes. About 15 minutes of every hour were shared to sketch echoes for the surveillance routine.

We shall briefly explain the purpose and the process of a quantitization. So far, many radar meteorologists have noticed the evolution/decay and translation of individual echo cell. In the present paper we like to express the rain activity in a scalar field of "echo coverage" which is defined as the ratio of an echo area to a grid area at a certain intensity level. This expression is convenient for some quantitative analysis method mentioned in the later section of the paper.

In order to quantitize radar echoes in the form of the echo coverage, we should specify the grid size and intensity level of echoes. Fig. 8 shows an example of PPI echoes at the three level levels which are available at the M-station. For simplicity we have selected level 4 only for quantitization. This level descriminates a significantly active rainfall area from a broad echo area, and the level gives the essential structure or behavior of the rainfall forming a rainband. According to the analysis of the raingauge data in Section 2, the horizontal extent of a significant convective area is ten kilometers or more. We have determined to adopt a square grid with $10 \mathrm{~km}$ and covered the domain $400 \times 400 \mathrm{~km}$ by $40 \times 40$ grids. This grid size depicts well the picture at gain level 4 . Fig. 9 shows the domain with a map of the Shikoku district and its surroundings. Quantitization into the form of the echo coverage has been performed manually by man's eye on each enlarged positive print and then the coverage has been classified into 10 classes with $10 \%$ intervals. We feel that the grid size is almost the minimum one which is tolerable to the errors in the processing of photos and in the estimation of an echo coverage. By the specification of the grid size and the gain level, we may express the echo coverage as $E(i, j, k)$, where $i$ and $j$ denote grid numbers in the $X$ (eastward) and $Y$ (northward) direction, respectively. The suffix $k$ stands for an observational time. The irregularity of a time interval of the observation is adjusted to 6 minutes by 

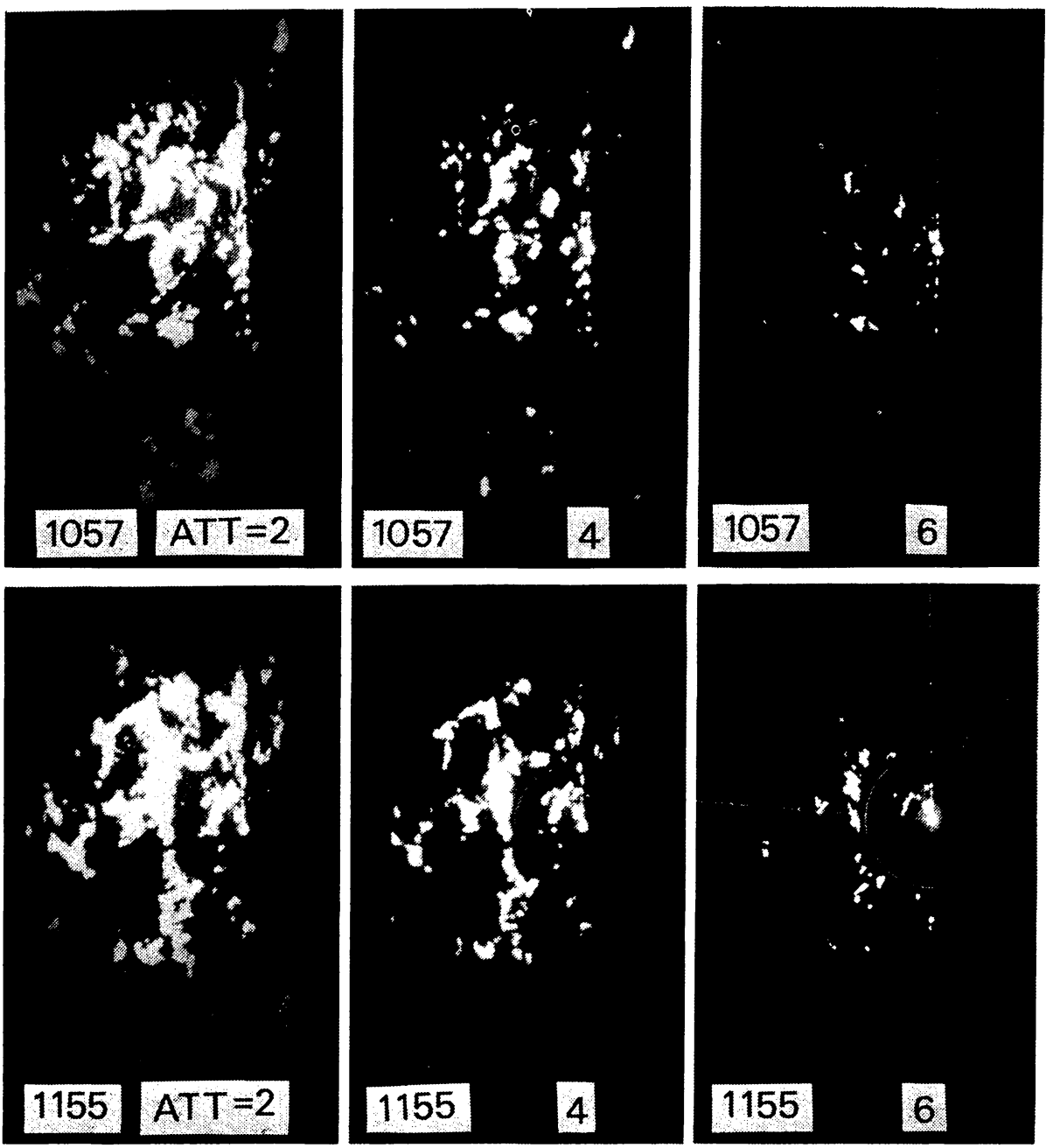

Fig. 8 PPI radar photos at Murotomisaki weather station at 1057 and 1155 JST on 11 September 1976 with three gain levels 2, 4 and 6. The range marks are $50 \mathrm{~km}$ interval with the elevation angle $1.5^{\circ}$.

linear interpolation.

\section{The mean radar rainband (MRB) and}

\section{variability in time}

In this section we shall at first estimate the mean states of rain activity revealed by radar for the two time scales 1 and 6 hours and compare them with the rainfalls. Later we shall discuss the time variation of rain activity.

\section{Mean state}

Mean echo coverage during $T_{p}$ may be written as

$$
\bar{E}\left(i, j, T_{p}\right)=\frac{1}{N_{p}} \sum_{k_{1}}^{k_{2}} E(i, j, k),
$$

where $T_{p}=\left(k_{2}-k_{1}+1\right) \Delta T, \quad N_{p}=k_{2}-k_{1}+1$ and
$\Delta T$ is the observational interval (in our case $\Delta T=6$ minutes). The mean echo coverage for $T_{p}=6$ hours 0900-1500 JST 11 September 1976 is shown in Fig. 10. At a glance we see a banded structure almost running longitudinally over Shikoku and Tosa Bay. The rain activity over the western and northern parts of Shikoku can not be detected well by the shadow effect of a mountain. In Fig. 10 we see the similar characteristic scales as mentioned in the 6-hour rainfall amounts in Section 2. First we recognize a macroscopic belt lying longitudinally with the west-east width of about $100 \mathrm{~km}$ over Tosa Bay and $200 \mathrm{~km}$ over Shikoku, which is denoted by the contour lines of $5 \%$ echo coverage. The belt can be devided into three zones over Shikoku. 


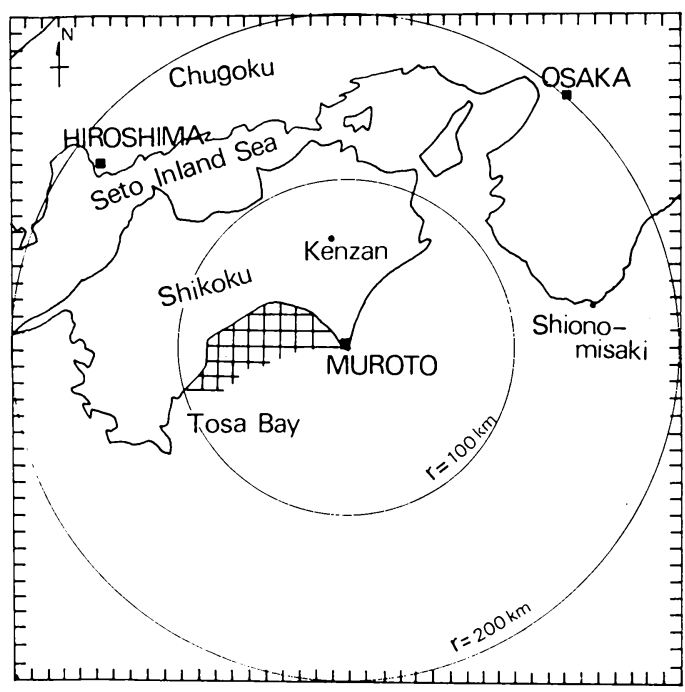

Fig. 9 The area over which PPI radar photos are quantitized, covering $400 \times 400 \mathrm{~km}$. Some square grids are shown over the Tosa Bay for a reference of the horizontal resolution.

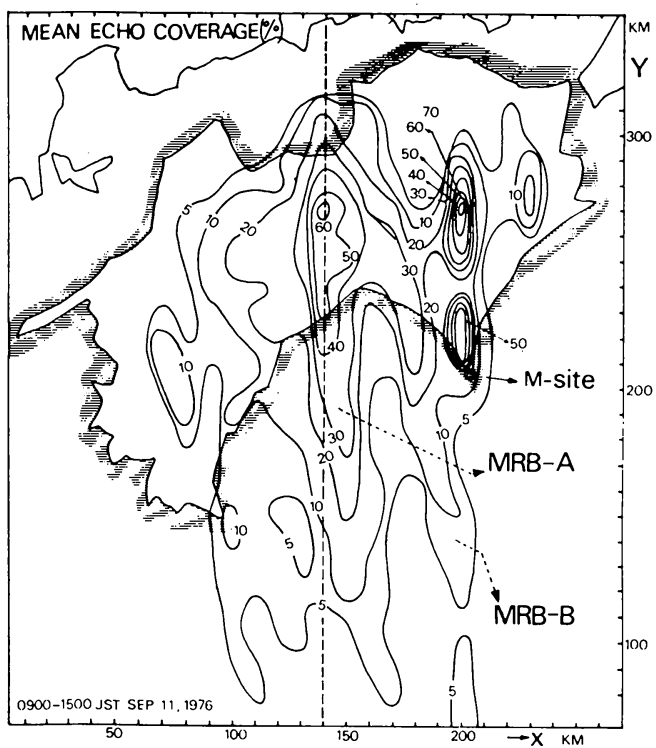

Fig. 10 Mean echo coverage (\%) over the Shikoku and Tosa Bay for the six hours from 0900 to 1500 JST on 11 September 1976. The letters MRB-A, B denote mean radar rainband.

The central zone is the typical one denoted by the contour line of $20 \%$ echo coverage. Over Tosa Bay, however, two bands exist with a narrow east-west extent in the belt, which have origines far south over Tosa Bay in the Pacific. We see the central band (Band A) extending longitudinally over the land and the Bay at least $250 \mathrm{~km}$. This band disappears over Seto Inland Sea behind the main mountain chains in Shikoku. The analysis of the radar echoes taken at Hiroshima and Osaka (See Fig. 9) shows that Band A extends over Seto Inland Sea but does not reach the Chugoku district. On the other hand we trace the existence of Band A southward at least $150 \mathrm{~km}$ from the coast of central Shikoku. Next the east band (Band B) is small compared to Band A. Bands A and B are separated over Tosa Bay, but over Shikoku they are merged. We may see another band which branches away from Band $B$ near the $M$-station northward and in which there exist two maxima.

We forcus our main concern on the features of Band A in Fig. 10. This is sharply defined with the contour line of $20 \%$ echo coverage over Tosa Bay with the east-west width of $20-30 \mathrm{~km}$. The width increases remarkably over the area where Band A lands on central Shikoku, showing about $70 \mathrm{~km}$. This extent corresponds to the zone scale mentioned before. We infer that this broadening of the rain activity is brought by an orographic effect. We recognize over the land the well-defined Band A of about $30 \mathrm{~km}$ in width and with the magnitude of about $40 \%$ in coverage. Let us see the north-south variations of the mean echo coverage in Bands A and B. The Mstation is preferably located to observe a main portion of Band A over Tosa Bay. That is, the major part of Band $\mathrm{A}$ is oriented along a tangent at the radius of $50 \mathrm{~km}$ from the M-station. The effects of the distance upon an underestimation of echo coverage is considered small except for a southern portion of Band A. This may be justified for Band B, too. The mean echo coverages along the main axes of Bands $A$ and $B$ are shown in Fig. 11. The coverage increases linearly

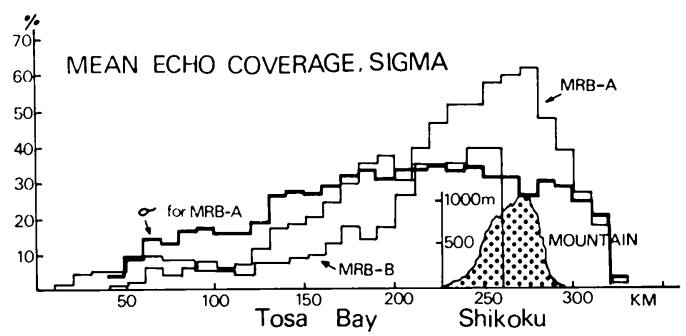

Fig. 11 Mean echo coverage along the main axes for the MRB-A and MRB-B. The thick line shows the standard deviation for the MRB-A. The north-south cross-section of Shikoku along the line at $x=140 \mathrm{~km}$ is shown by the stipple. 
toward the land, showing that the rain activity becomes strong toward the land. The orography of Shikoku concaving toward Tosa Bay (Sec Fig. 10) acts as a barrier against southerly winds and may bring a longitudinally concentrated updraft over Tosa Bay. We consider that the increase of the echo coverage or of the total rainfalls along Bands $\mathbf{A}$ and $\mathbf{B}$ are primarily due to such orographic effects. We have obtained Bands A and $B$ as the mean coverage for the six hours. We therefore refer these bands to the Mean Radar Rainbands A and B (MRBs A, B).

At this stage we shall discuss how these radarrain/belt/zone/band relate to those which were analyzed by the conventional raingauge rainfall over Shikoku mentioned in the previous section. Comparing Fig. 3 with Fig. 10, we see a good correspondence between the location and the horizontal extent of the belt. We see a similar zone-scale distribution over Shikoku. Over Tosa Bay, however, the zone scale shrinks to a band scale. It should be noted that the central band is well defined in both figures at the same region over the land. This means that severe rainfall over the land is closely connected with rain activity over Tosa Bay. Figs. 3 and 10 show that we have a narrowly concentrated rainfall with the amount of $100 \mathrm{~mm} / 6$ hours over Tosa Bay, too.

Next we shall note the mean state of the echo coverage for the time scale one hour. In Fig. 12 the mean state is shown in terms of an accumulated time. The characteristics of the hourly rain activity in Fig. 12 are almost similar to those for the time scale of 6 hours, but the longitudinal scales are different between them. In Fig. 12 we recognize several localized areas in the central rainband, which are longitudinally separated by several tens of kilometers. Corresponding to one of the localized area above, we have a localized severe rainfall area obtained by raingauge over Shikoku in Fig. 4. This means that severe rainfall over Shikoku is brought by the passage of several rain complexes, and the pass of them are concentrated into longitudinal bands which are stationary to the ground.

From the above analysis we conclude as follows. The areas of a significant rainfall are not distributed at random, but are organized within several banded-regions. The most active rainfall takes place within a long, narrow band both over Shikoku and Tosa Bay. The intensity and the horizontal extent of the rainband increase over ocean toward land. We have a second con-

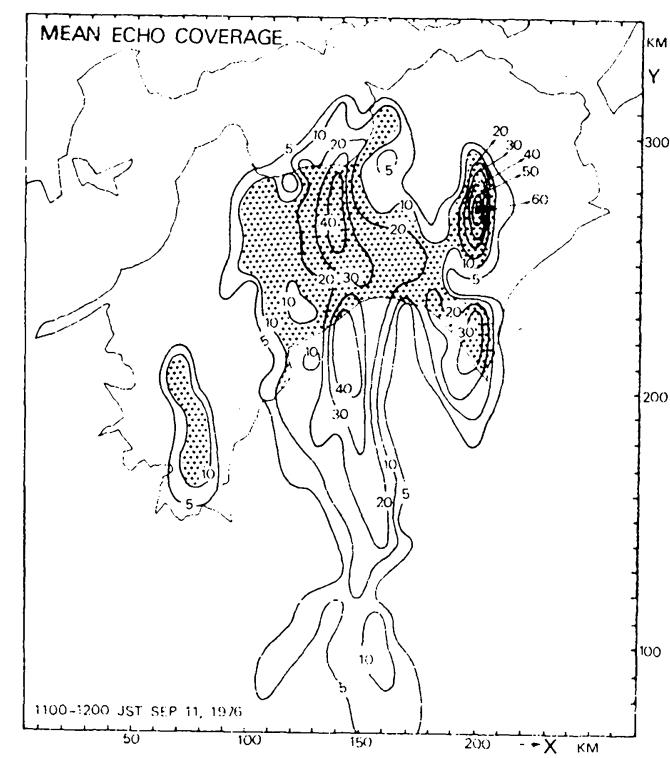

Fig. 12 Mean state of echo coverage during the one hour from 1100 to 1200 JST on 11 September 1976. 'The accumulated time in minute, which is defined as the summation of the product of an echo coverage and the time increment $\Delta T=6$ minutes, is used for unit. The regions with more than 10 minutes are stippled only over Shikoku.

centration of rain activity in the zones mainly over Shikoku. The rainband and zone are embedded in the rain belt with the scale of an outer spiral rainband of typhoon.

\section{Time variation}

In Section 2 we showed that the rainfall over Shikoku was highly characterized by pulsative convections. It is interesting to see a pulsative property of rain activity which may prevail in rain belt and how it is modified over the field from ocean to mountain range. In order to see the pulsative component of rain activity we have estimated the variance as

$$
\sigma_{N}^{2}(i, j)=\frac{1}{N} \sum_{k=1}^{N}\{E(i, j, k)-\bar{E}(i, j)\}^{2} \cdot !
$$

We also define the relative variability for $E$ as

$$
V(i, j)=\frac{\sigma_{N}(i, j)}{\bar{E}(i, j)}
$$

where $\sigma_{N}$ is the standard deviation. The variability $V$ may be interpreted, in other words, as an indication of steadiness of the rain activity.

The horizontal distributions of $\bar{E}$ and $\sigma_{N}$ are shown with $V$ in Figs. 13a, b and c. The magnitude of the standard deviation is rather uniform 

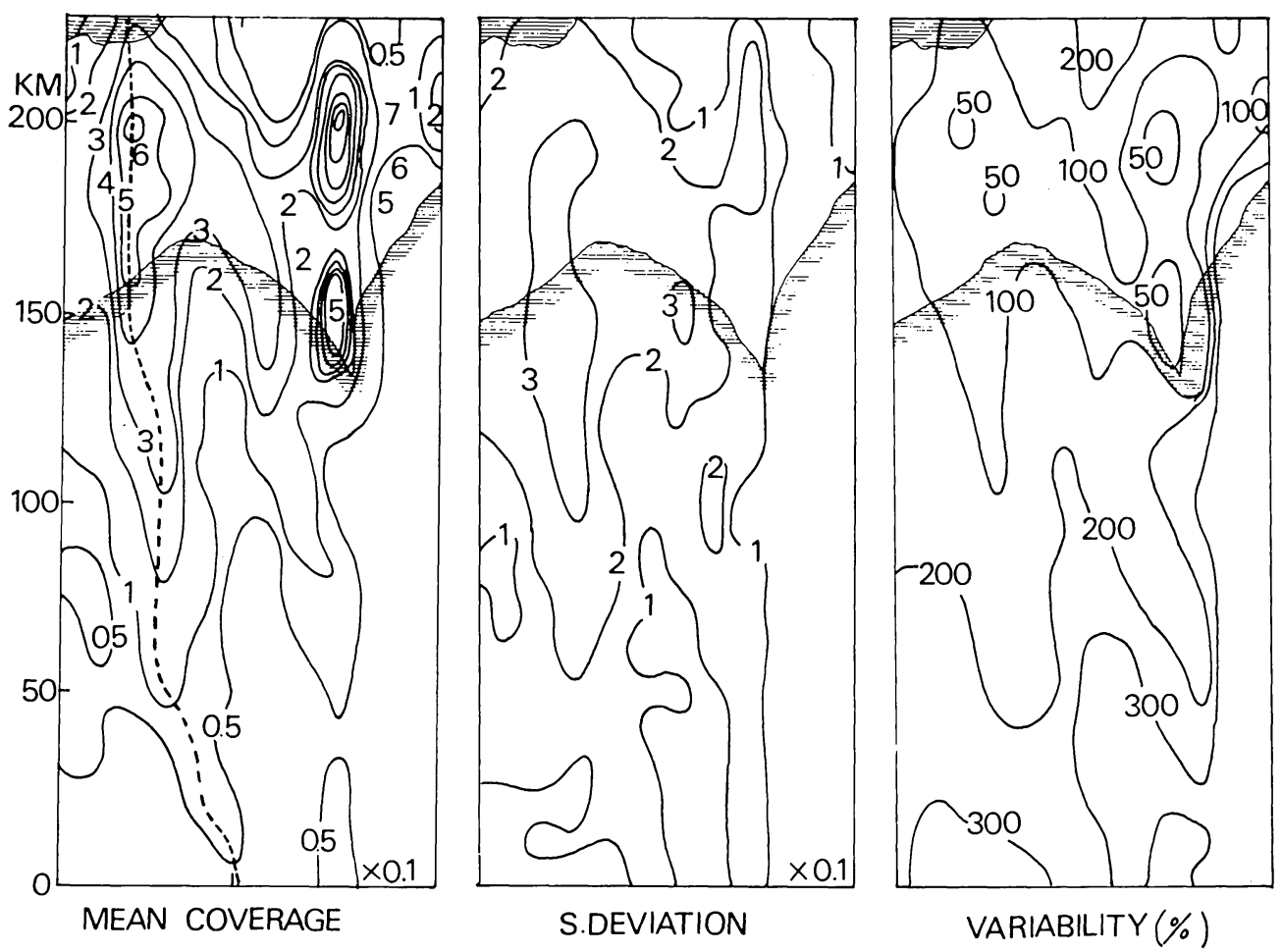

Fig. 13a, b, c (a) Mean echo coverage for the six hour from 0900 to 1500 JST on 11 September 1976. The thick dashed line shows the main axis for the MRB-A. (b) Standard deviation for echo coverage. (c) Variability which is defined as the ratio of the standard deviation to the mean echo coverage.

compared with the mean echo coverage. We see that the major rainbands are almost identified by the contour of $\sigma_{N}$ with $20-30 \%$. It is noted that the rain activity has a uniform magnitude of variance in Band $\mathrm{A}$ in spite of the increase of the mean echo coverage toward Shikoku. This is well seen in Fig. 11. It is also important to note that the $\sigma_{N}$ has almost the same magnitude as the mean echo coverage over Tosa Bay and over the peripheral region of Band $\mathrm{A}$. This is well shown in Fig. $13 \mathrm{c}$ that the variability $V$ is about $100 \%$ or more over those regions. That is, the rain activity is highly pulsative there. We still have the same pulsative feature both over the coastal and mountain regions, where the mean echo coverage is large. Over those regions the magnitude of $V$ is less than $100 \%$ in Fig. 13c. We have a similar feature for Band B, though it is not so clear as for Band A. Akiyama (1978) showed that the standard deviation rises 1.5 times the amount of the rainfall in the heavy rainfall zone in Baiu Front. It is interesting to note that there exists a similar correspondence in the transient property of rainfall in spite of the different situation.

\section{Spectral analysis of the time series of the echo coverages}

In the previous section we obtained the mean radar rainbands $A$ and $B$ (MRBs $A, B$ ). In this section we performed spectral analyses of the time series of the radar echo coverage, $E(i, j, k)$ which were defined in Section 3 at each grid, in order to study the time scales of rain clouds which form the rain belt. The number of the quantitized radar data is 64 with 6 minutes time interval at each grid point. We shall be concerned with a predominant period which ranges between 38.4 and 128 minutes.

At first it is interesting to see the horizontal distribution of the predominant period. In Fig. 14 the distribution is shown in the rain belt. The period about one hour remarkably prevailed over the whole region. However, if we examine each predominant period individually, we see they are not necessarily similar. Some times they differ 


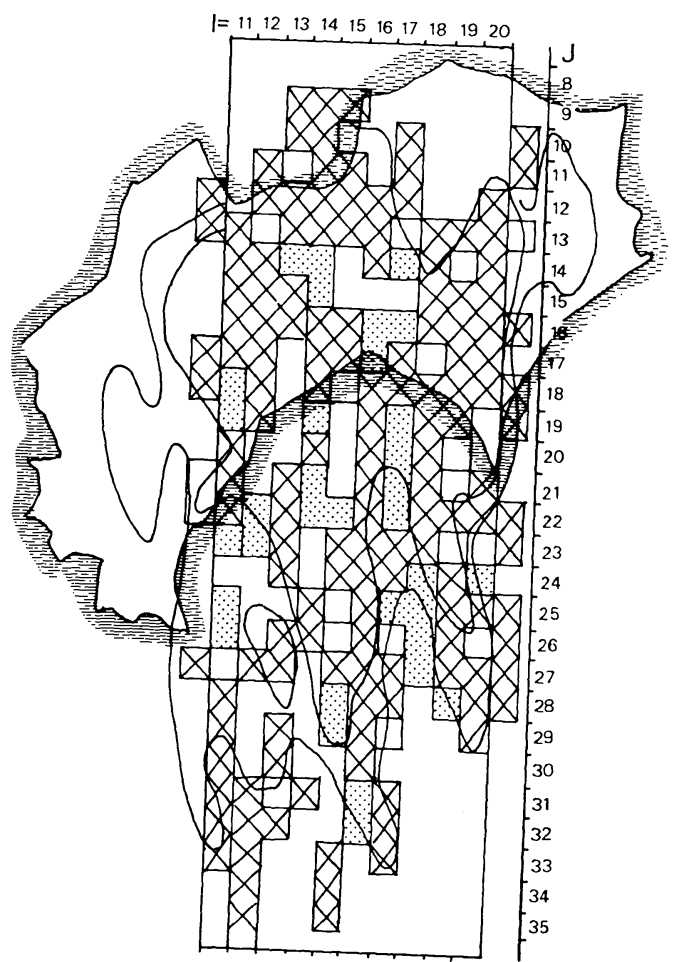

Fig. 14 Horizontal distribution of the predominant period which is obtained from the spectral analysis in time series of echo coverage at each grid. The regions with the periods 55,64 and 77 minutes are shown by cross. The stippled region denotes the periods 48 and 43 minutes. The blanked region shows the periods 96 and 128 minutes or no predominant period. The solid curved line denotes the total echo coverage of $5 \%$.

even between adjacent grid points. There seems to be no essential differences between the periods over sea or over land or between the core and the periphery of the MRBs. We decided to see significant time scales of the rain clouds in the rectangular region $100 \times 200 \mathrm{~km}$ in Fig. 14. The frequency distribution of the predominant period is shown in Fig. 15, which is counted over the rectangular region (note that the frequency is presented in units of percentage). We see that about $70 \%$ of the predominant periods fall in the periods 55 to 77 minutes. Some typical spectra are represented in Fig. 16 in which the solid lines denote the spectra for mountain regions and the dashed line for Tosa Bay. The period of around one hour prevails in Fig. 16. The figure shows that the squares of the amplitude for the predominant wave are in the order of 0.01 ,

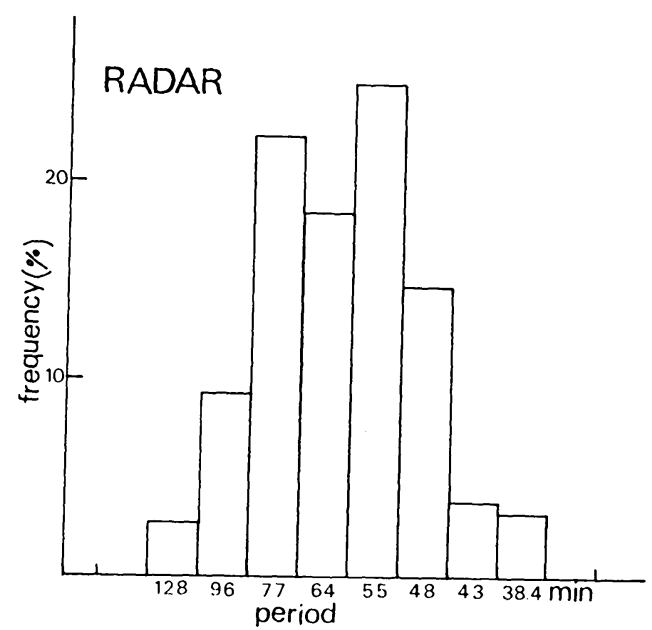

Fig. 15 Frequency distribution of the predominant period estimated over the rectangular area in Fig. 14.

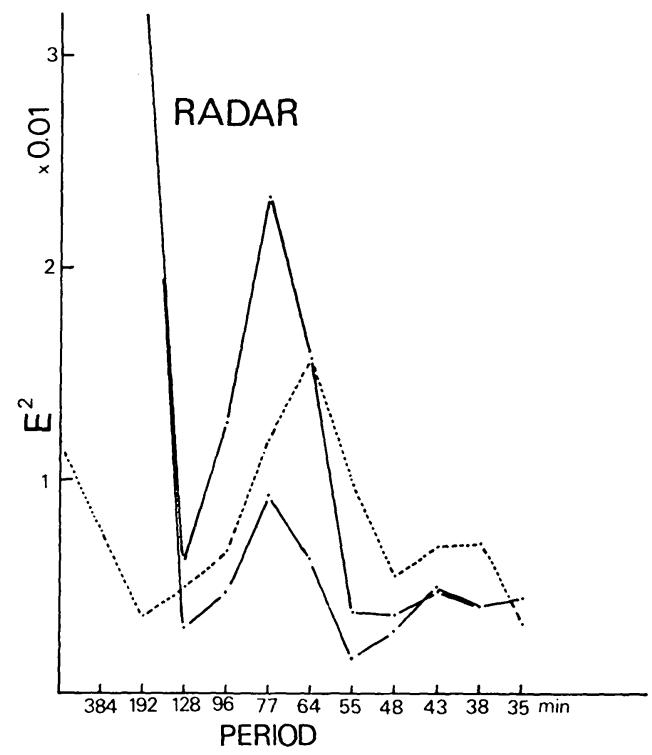

Fig. 16 Examples of spectrum. The solid lines shows the spectra for the rainfall activity over Shikoku and the mountain range, and the dashed line for over the Tosa Bay.

indicating that the amplitude is about 0.1 (That is $10 \%$ in echo coverage). We shall now estimate how this predominant wave occupies the variance field. The amplitude-square which is anticipated from the predominant period and both its adjacent periods, is about $0.04-0.09$. Thus it is considered that a variable component of the rainfall activity consists largely of the predominant wave having the period of one hour. 


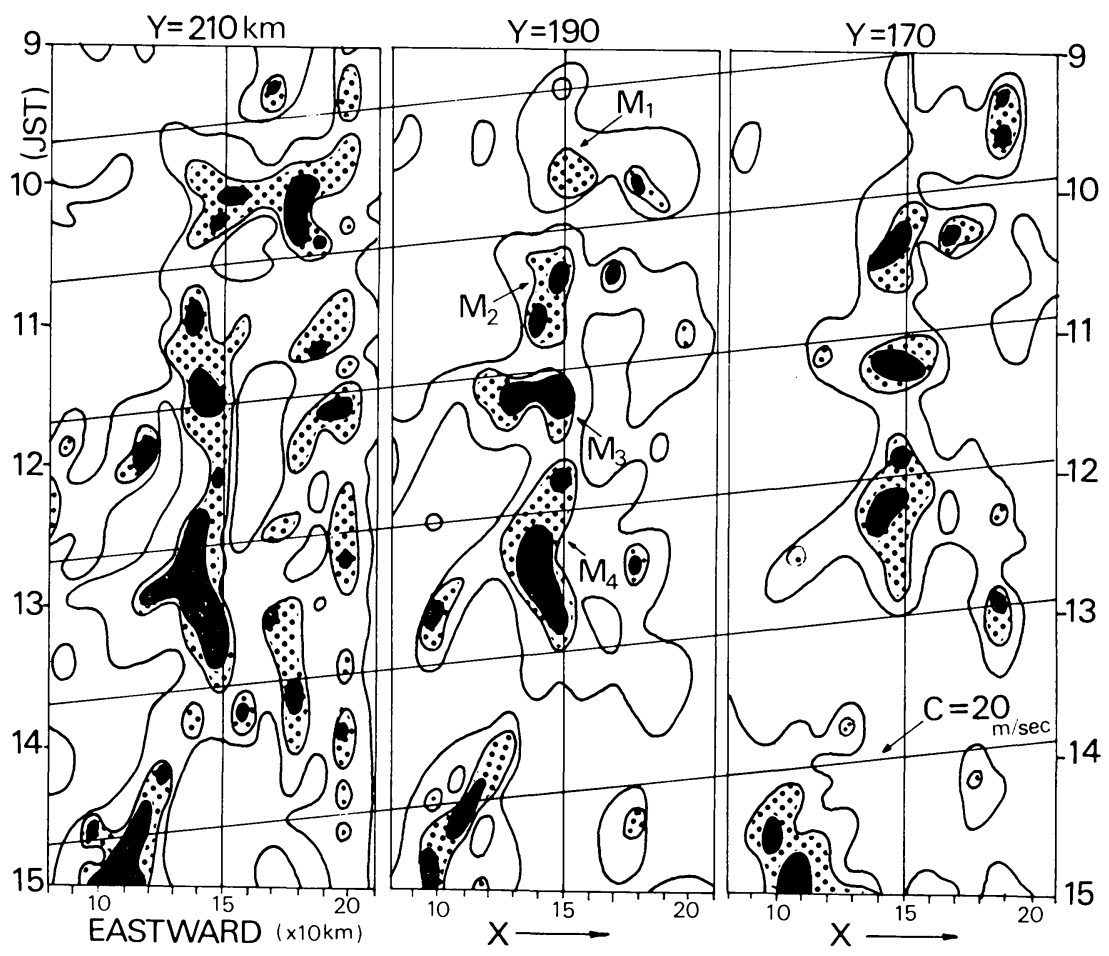

(c)

(b)

(a)

Fig. 17a Time-space cross section of echo coverage at $Y=170 \mathrm{~km}$. The coordinates $X, Y$ are the same as in Fig. 10. The echo coverage with more than $80 \%$ is shown by black and that between $50 \%$ and $80 \%$ by stipple. The solid curved lines enclose outer edge of echoes. The slanted straight lines represent a reference travelling speed, $C=20 \mathrm{~m} / \mathrm{sec}$, along the longitude at $x=150 \mathrm{~km}$. Fig. $17 \mathrm{~b}$ The same as Fig. $17 \mathrm{a}$, but at $Y=$ $190 \mathrm{~km}$. Fig. $17 \mathrm{c}$ The same as Fig. $17 \mathrm{a}$, but at $Y=210 \mathrm{~km}$.

Here let us discuss this predominant rain activity based on several time space cross sections of the original data $E(i, j, k)$. The sections are shown in Fig. 17a-f along the six different latitudes with $20 \mathrm{~km}$ intervals. The area of more than $80 \%$ coverage in $E(i, j, k)$ is shown by black and those of more than $50 \%$ by stipple. It seems that at each latitude rain clouds appear intermittently along the longitude with various time and horizontal (west-east) scales. It is noted that major travelling routes of the rain clouds are confined to a few longitudes. These routes are along the longitudes at $x=140-150 \mathrm{~km}$ and $x=$ $180-190 \mathrm{~km}$ over Tosa Bay. The routes are reflected well in the mean echo coverage in Fig. 10 as the MRB-A, B. Our concern is with the rain clouds which are associated with the MRBA. In each of Figs. 17a-f we see several domains with $50 \%$ echo coverage which have at least one domain with $80 \%$ echo coverage inside. For example, we may indicate such domains in Fig. $17 \mathrm{~b}$ by the letters, $M_{1}, M_{2}, M_{3}$ and $M_{4}$. We also see that the east-west extent of such domains is about $30 \mathrm{~km}$, which is representatively defined by $50 \%$ echo coverage. The difference of the extent along the longitude is very small. It is possible to interpret the above domain like $M_{4}$ as a rain cloud complex or as a convective rain complex (CRC) which includes more than one cumulus convection. It is considered that the significant rainfall is confined within CRC. We see that at each latitude rain clouds appear to be separated with time. It also seems that CRC appears repeatedly with the period of about one hour. Thus we interpret the data to mean that the predominant rain clouds obtained by the spectral analysis correspond to the convective complex which appears with the period of one hour and with the significant east-west extent of $30 \mathrm{~km}$. 


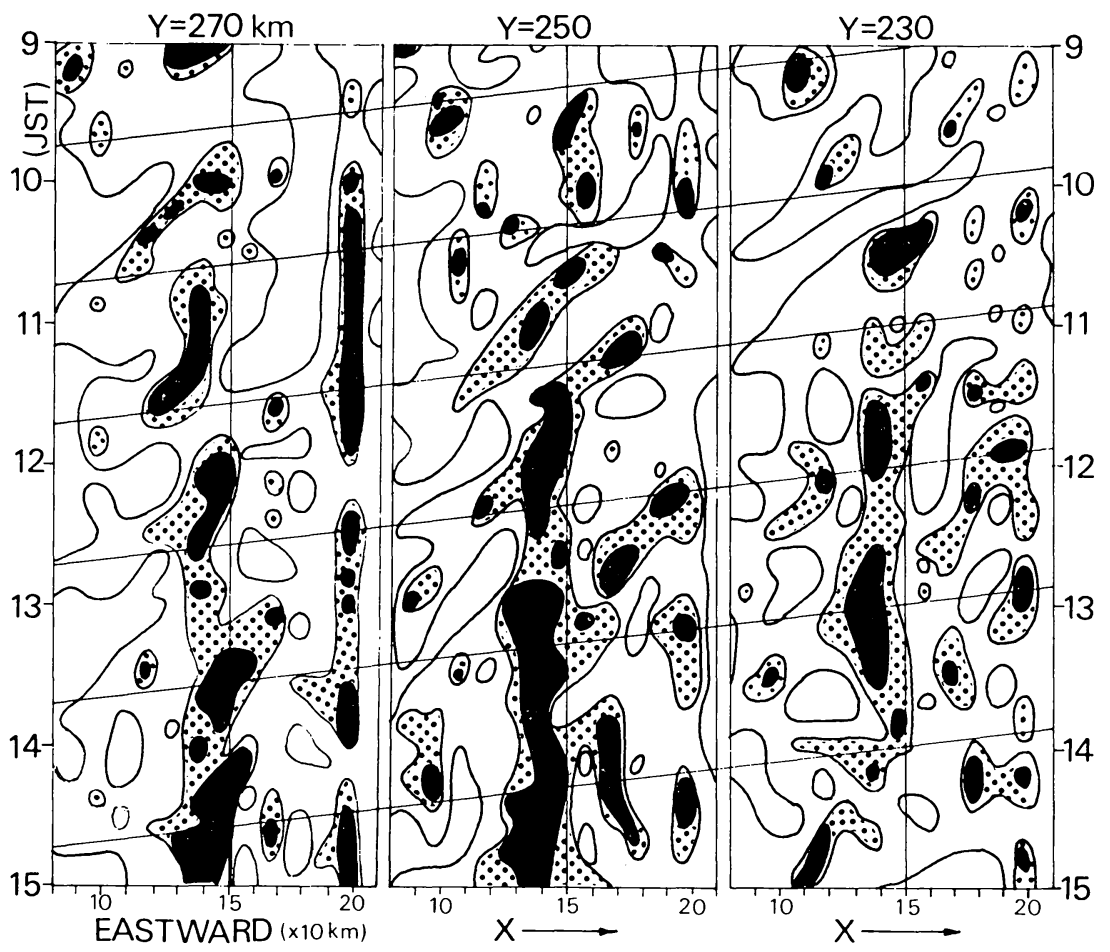

(f)

(e)

(d)

Fig. $17 \mathrm{~d}$ The same as Fig. 17a, but at $Y=230 \mathrm{~km}$. Fig. $17 \mathrm{c}$ The same as Fig. $17 \mathrm{a}$, but at $Y=250 \mathrm{~km}$. Fig. 17f The same as Fig. 17a, but at $Y=270 \mathrm{~km}$.

\section{Time-space spectral analysis}

In the preceding section we have revealed the predominant period among convective rain complexes which travel northward in the MRB-A. Here we are concerned about how the period is related to the north-south scale and to the travelling speed of the CRCs. That is, it is interesting to see how a predominant horizontal scale with a predominant travelling speed cxists among the CRCs in the MRBs. For this purpose we performed a two-dimensional (time-space) spectral analysis upon the echo coverage $E(i, j, k)$ which was defined in Section 3. We used the subroutine program of the Fast Fourier Transform developed at National Center for Atmospheric Research, U.S.A. For the space coordinate we selected longitude since the travelling of the rain clouds was almost confined along longitude. We estimated a two-dimensional spectrum along each longitude with $10 \mathrm{~km}$ intervals from $x=100$ to $220 \mathrm{~km}$. The longitude crossing at $x=120 \mathrm{~km}$ is oriented along a western periphery of MRB-A and that at $x=140 \mathrm{~km}$ is almost along the main axis of MRB-A. These longitudes are shown in
Fig. 10. The two-dimensional spectra along the three different longitudes $x=120,130$ and 140 $\mathrm{km}$ are shown in Figs. $18 \mathrm{a}, \mathrm{b}$, c. We subtracted preliminarily the mean value for both time and space from the original data in each case. The magnitude of the spectra in the figures are normalized by maximum value in each case. These processes make it easy to represent the spectra systematically.

Let us first examine the spectrum in Fig. 18a which was obtained along the western peripheral section of the MRB-A. We see that there exists a predominant scale with the wave number around $n=4$ in rain activity. This scale corresponds to the north-south wavelength $L=80 \mathrm{~km}$ since the total north-south span was taken to be $320 \mathrm{~km}$. An extent of the closed contour line with the magnitude of 100 shows that the predominant period and wavelength fall between 55 and 77 minutes, and between 64 and $107 \mathrm{~km}$, respectively. This makes the phase speed ranging from 14 to $32 \mathrm{~m} / \mathrm{sec}$. This period is consistent with the results obtained in the preceding section. Next we show in Fig. $18 \mathrm{~b}$ the spectrum obtained along the longitude crossing at $x=130 \mathrm{~km}$. We 


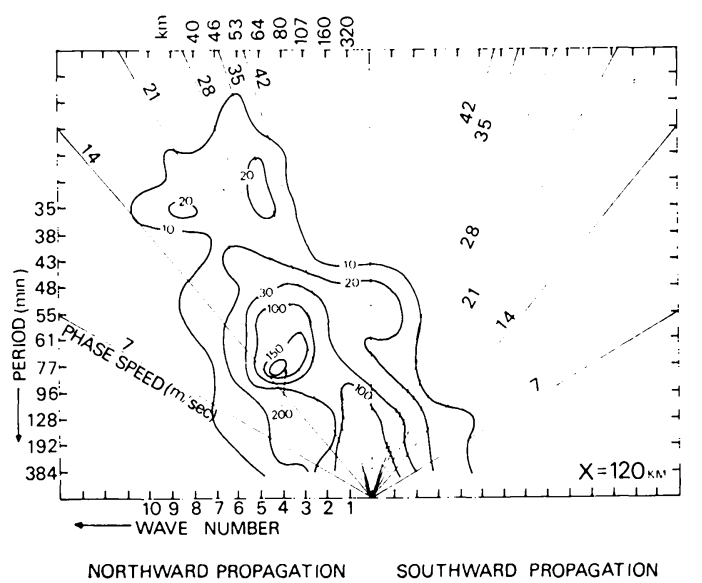

Fig. 18a Two-dimensional spectral analysis. The space coordinate is taken along the longitude crossing at $x=120 \mathrm{~km}$.

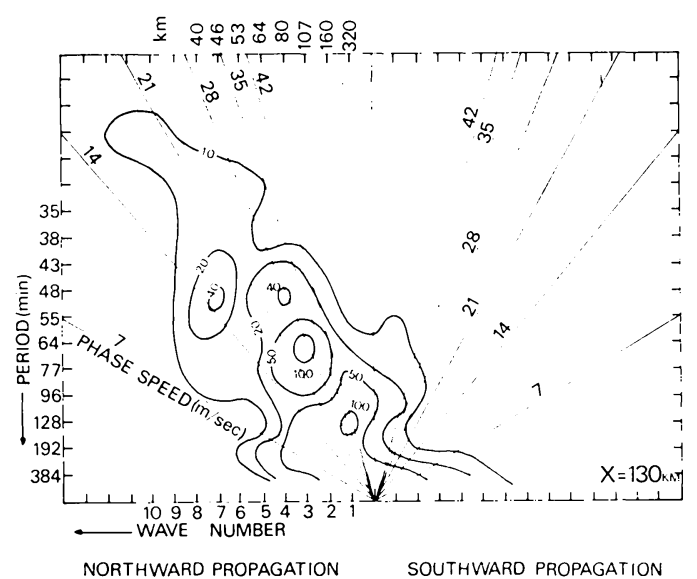

Fig. 18b The same as Fig. 18a, but at $x=130 \mathrm{~km}$.

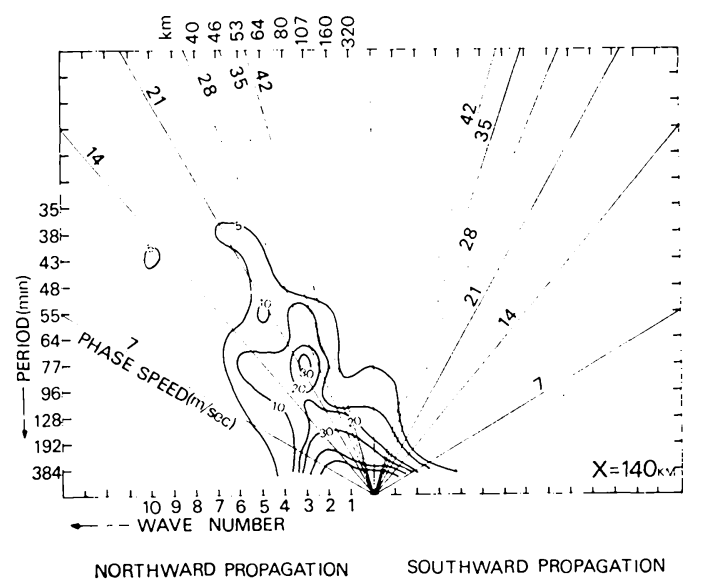

Fig. 18c The same as Fig. 18a, but at $x=140 \mathrm{~km}$. also see a similar feature for the section at $x=$ $120 \mathrm{~km}$, though the second maximum appears at around $T=50$ minutes and $L=50 \mathrm{~km}$. The spectrum obtained for the main axis of the MRB$A$ is shown in Fig. 18c. We still see that a predominant period is centered around 77 minutes, which is similar to that obtained along the other two longitudes. The predominant wavelength is, however, centered at $L=107 \mathrm{~km}$, which is rather long compared to the others. The phase speed of this wave is about $20 \mathrm{~m} / \mathrm{sec}$. A predominance of the wave in the spectral spaces seems not so remarkable as for the waves at $x=120$ and $130 \mathrm{~km}$.

For the understanding of the waves obtained mathematically above, we further refer to the space-time cross sections of $E(i, j, k)$ along the longitudes corresponding to those in Figs. 18a, $\mathrm{b}$, and $\mathrm{c}$ respectively. The space coordinate is taken toward the north in Figs. 19a, b and c, and the echo coverage are classified into 3 ranks as in Figs. 17a-f. We may recognize in Figs. 19a, b, c several convective rain complexes, which are labelled by the letters $C_{1}, C_{2}, \ldots, C_{6}$, travelling northward in a regular manner. The slanted parallel and straight lines in Fig. 19a are drawn subjectively to connect core portions which are expressed by large echo coverage. Similar straight lines in Figs. 19b, c are simply copied from those in Fig. 19a. It should be noted that we can trace a convective rain complex more than several hours along the same phase line. We see similar characteristics in Figs. 19c. In Fig. 19a CRCs likely travel northward with a speed $C=20 \mathrm{~m} /$ sec. Along the main axis of the MRB-A in Fig. 19c we still detect such travelling of the CRCs. We see a linearly increasing trend along the longitude (at $x=140 \mathrm{~km}$ ) in the time-averaged echo coverage in Fig. 11. We also see in Fig. 19c a spacious trend between land and sea in echo coverage. This trend weakens the predominance of the wave in Fig. 18c. We have obtained a predominant wave, $T$ is around 77 minutes, $L$ is ranging 60 to $100 \mathrm{~km}$ and $C$ is $15-25 \mathrm{~m} / \mathrm{sec}$, by the use of the filtered data in which the trend above is eliminated.

We interpret the results of the spectral analyses above as follows. Individual convective rain clouds are embedded with concentration in a narrow belt, which forms a mean radar-rainband in both and time. In the rainband there exist well isolated complexes of rain activity, CRCs, travelling northward with a predominant wavelength and speed. The predominant wavelength 


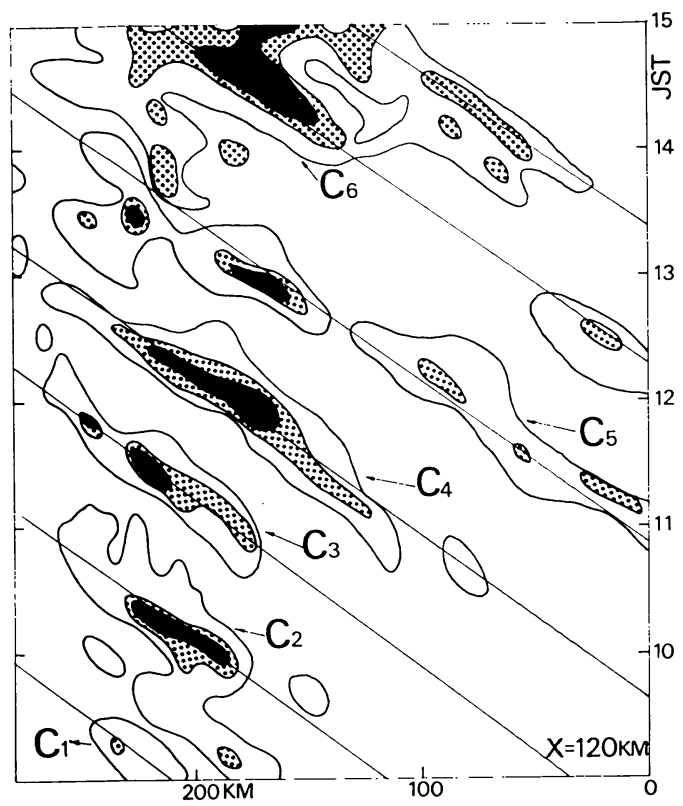

Fig. 19a Time-space cross section for echo coverage. The space coordinate is taken along the longitude crossing at $x=120 \mathrm{~km}$. The amount of the echo coverage is shown in the same manner as Figs. 17a-f. The letters, $C_{1}, C_{2}, \ldots, C_{6}$ denote rain cloud complex, respectively. The slanted lines show the northward travelling speed with $C=21 \mathrm{~m} / \mathrm{sec}$.

should be considered as a characteristic separation distance for CRCs along longitude. It is noted that the predominant period of one hour obtained through the spectral analysis does not mean the lifetime of individual cumulus convections. The travelling speed obtained from the spectral analysis is almost the same as that of individual echoes. The speed $20 \mathrm{~m} / \mathrm{sec}$ is faster than a general current anticipated from the upper soundings at Shionomisaki and Mt. Kenzan showing about $16 \mathrm{~m} / \mathrm{sec}$.

\section{Summary and concluding remarks}

In order to see the time and horizontal scales of rainfall activity in the so-called outer rainband associated with typhoons and their relations with orography, the conventional PPI radar echoes were analyzed by quantitizing them in the form of echo coverage within a $10 \mathrm{~km}$ square grid. We obtained some characteristic features of the mean state and the variability of embedded rain clouds in time and space, mainly by the use of one- and two-dimensional spectral analysis. We

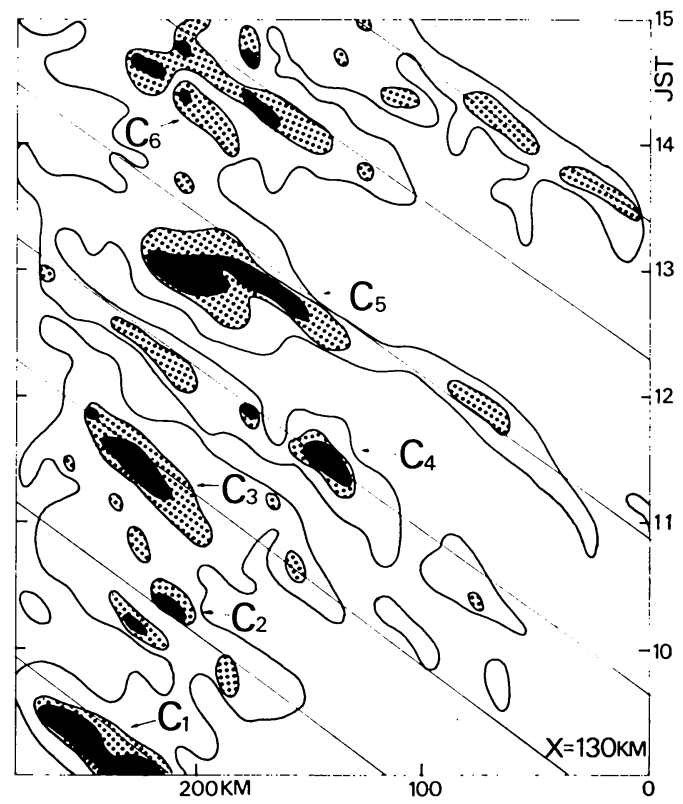

Fig. 19b The same as Fig. 19a, but at $x=130 \mathrm{~km}$.

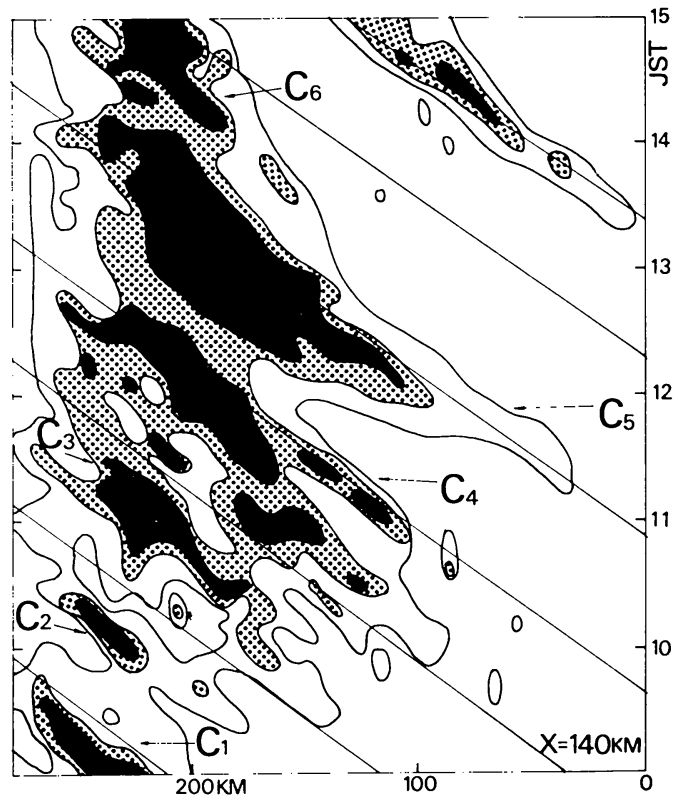

Fig. 19c The same as Fig. 19a, but at $x=140 \mathrm{~km}$.

summarize the major results as follows, though these are descriptive at this stage. (1) We recognize a few characteristic scales in the mean rainfall activity. There exists the rain belt over Shikoku and Tosa Bay extending a few hundreds kilometers along longitude. The west-east width is about $200 \mathrm{~km}$ over the land and $100 \mathrm{~km}$ over the bay. Next the main rainband is revealed lying 
longitudinally over central Shikoku and Tosa Bay in the rain belt. The longitudinal extent is the same as that of the rain belt and a characteristic width of the rainband is about $30 \mathrm{~km}$. The rainband runs almost parallel to the prevailing wind direction (SSE) associated with Typhoon 7617. The amount of the echo coverage along the main axis of the rainband increases almost linearly toward inland Shikoku. According to satellite pictures, the rain belt including rainbands is considered to form a part of outer spiral bands of the typhoon. It is inferred that an outer rainband of the typhoon is trapped and intensified by an orographic effect that a southward-concave topography of Shikoku acts as barrier against the southerly winds associated with the typhoon and forms a convergence zone over the central Shikoku and Tosa Bay. This orography induced convergence is favourable to generate rainfall activity. (2) We have a variance with a uniform magnitude in the time series of the echo coverage in the longitudinal belt which crosses over the mountain range far from the south in Tosa Bay, and which overlaps almost to the region of the mean rainband. It is noted that the magnitude of the standard deviation on the echo coverage is about $20-30 \%$, which is comparable to that of the mean coverage over Tosa Bay and which is more than half of the mean coverage over the land. In this sense the rainfall activity is highly pulsative in the rainband. (3) The spectral analysis for the time series of the echo coverage shows that the rainfall activity has the predominant period of one hour. It is considered that the rainband consists of convective rain complexes (CRCs) with the period. It is noted that we have obtained a similar period over both the land and the mountain range. (4) The two-dimensional (space-time) spectral analyses along the rainband showed that CRCs are isolated along longitude in a regular manner. We obtained a well defined peak for echo coverage in the spectra. We interpret our data to indicate that CRCs are statistically embedded in the wave as if the wave propagates with a predominant period and a wavelength. The period is one hour corresponding well to the predominant period revealed by the one-dimensional spectral analysis. The wavelength is about $50-100 \mathrm{~km}$ and it should be considered as the characteristic separation distance for CRCs. The propagation speed of the wave is about $20 \mathrm{~m} / \mathrm{sec}$.

This work is the first stage in aiming to understand the features of rainfall activity over land and sea. The main concerns were devoted to description of statistical features by quantitizing PPI radar data. It should be noted that the six hour data are insufficient to make the above results conclusive at this stage. We are processing radar data for an extended period and area which are covered by several radar sites. We have a plan to synthesize our results with other meteorological variables. It remains to study why sharply defined narrow rainbands stayed longitudinally over Shikoku and Tosa Bay. There are documents asserting that outer spiral rainbands associated with typhoon generally propagate radially outward (Senn and Hiser 1959, Ushijima 1958, Staff Members of Tokyo Univ. 1969, Willoughby 1978 etc.).

\section{Acknowledgements}

The author wishes to express his sincere thanks to Professor R. Sawada, Kyushu University, for his hearty encouragement. The author also thanks Dr. M. Okuta and Mr. M. Tosha, Meteorological Research Institute, in assisting him to perform this work. The author acknowledges the cooperation of many public and private organizations in collection of the meteorological data. The author is indebted to Professor T. Asai, Ocean Research Institute, University of Tokyo, for the financial support for the data collection in western Japan. The author thanks Dr. K. Ninomiya, Japan Meteorological Agency, for his valuable advices to improve the manuscript. The writer wishes to thank Professor Frederick P. Harris, Waseda University, who gave many valuable suggestions for the improvement of the exposition.

\section{References}

Akiyama, T., 1974: Mesoscale organization of cumulus convection in the large-scale rainband in the Baiu season. J. Meteor. Soc. Japan, 52, $448-451$.

1978: Mesoscale pulsation of convective rain in medium-scale disturbances developed in Baiu front. J. Meteor. Soc. Japan, 56, 267-283.

Ninomiya, K. and T. Akiyama, 1974: Band structure of mesoscale echo clusters associated with lowlevel jet stream. J. Meteor. Soc. Japan, 52, 300 313.

Ninomiya, K., 1977: A note on the heavy rainfalls over South Shikoku. Tenki, 24, 105-112 (in Japanese).

Sakakibara, H. and T. Takeda, 1973: Modification of Typhoon 7002 rainfall by orographic effect. J. Meteor. Soc. Japan, 51, 155-167.

Senn, H. V. and H.W. Hiser, 1959: On the origin 
of hurricane spiral rain bands. J. Meteor., 16 , 419-426.

Staff Members, Division of Meteorology, Tokyo Univ., 1969: Precipitation bands of Typhoon Vera in 1959 (Part 1). J. Meteor. Soc. Japan, 47, 298-309.

1970: (Part 2). J. Meteor. Soc. Japan, 48, 103-117.

Suzuki, H., 1961: A predicting method of the rainfall distribution of typhoons over Shikoku. The Shikoku district meteorological research notes (in Japanese).

Tatehira, R., 1961: Radar and meso-scale analysis of rainband in typhoon. Case study of Typhoon Helen (No. 5821). J. Meteor. Res., 13, 264-279 (in Japanese). , 1962: Radar and meso-scale analysis of rainbands in typhoon Georgia in 1959-Comparison with the case of Typhoon Helen in 1959. J. Meteor. Res., 14, 621-630 (in Japanese).

Ushijima, T., 1958: Outer rain bands of typhoons. J. Meteor. Soc. Japan, 36, 1-10.

Willoughby, H. E., 1978: A possible mechanism for the formation of hurricane rainbands. J. Atmos. Sci., 35, 838-848.

\title{
定量化されたレーダ資料を用いた台風の降雨帯の研究
}

\author{
古川武彦 \\ 気像研究所
}

台風7617号に対する PPI レーダェこーを，等厅岬を中心とした $400 \times 400 \mathrm{~km}$ の領域にわたり $10 \mathrm{~km}$ 格子内に占

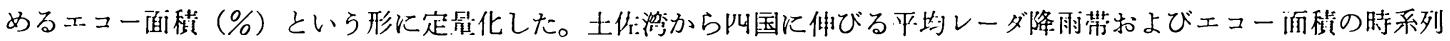
における変動性を，榭忙計による降雨琵と関連させて論じた。

顕著な降雨带は平均状態では 2,3 個の狭いバンドに集中して扣り，それらは台風に伴う卓越風向に殆んど平行に走 っている。ヨ:たるバンドはその強さ及び東西幅を增しながら洋上から四同内陸に闬って直任に俳びている。平均レー

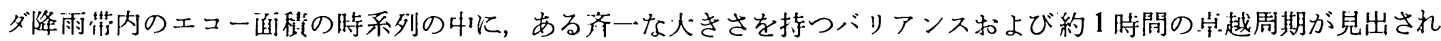

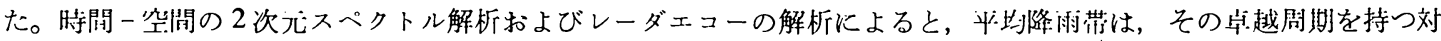

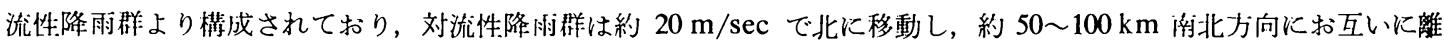
れていると考えられる。 